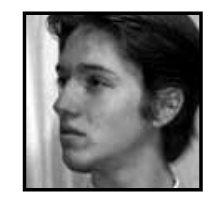

\title{
Passion by Design: Meditations on an Innovative Model
}

\section{Eli Gerber}

\section{ABSTRACT}

In this article the author discusses two intrinsically interrelated items: first, the past, present, and future of the educational infrastructure as well as its purpose, potential, and shortcomings; and second, the unique nature of his home school education. He further examines related elements that are conducive to the enrichment of the current educational model and also that of social development in general. His underlying goal is to inspire reflection on the importance of fully promoting passion, diversity, creativity, introspection, and innovation.

It is, in fact, nothing short of a miracle that the modern methods of instruction have not yet entirely strangled the holy curiosity of inquiry; for this delicate little plant, aside from stimulation, stands mainly in need of freedom; without this it goes to wreck and ruin without fail. It is a very grave mistake to think that the enjoyment of seeing and searching can be promoted by means of coercion and a sense of duty. To the contrary, I believe it would be possible to rob even a healthy beast of prey of its voraciousness, if it were possible, with the aid of a whip, to force the beast to devour continuously, even when not hungry, especially if the food, handed out under such coercion, were to be selected accordingly. (Einstein, 1949, p. 17)

\section{Overview of the Educational Infrastructure}

ducation has evolved into a richly dimensional and intricate topic of political, social, economic, and scientific discussion. Over the course of my fledgling academic career, I have been fortunate enough to collaborate with 
many intellectually engaged people. I have observed that each one of these individuals -irrespective of their cultural, professional, and personal backgrounds-possesses a meticulously honed and definitively tenacious opinion about education. It is a topic that is often intrinsically linked with our sense of self, thus its sensitivity runs deeply in so many of us. One explanation of this phenomenon is that education is a fundamental foundation of society and civilization. In a universe where infinitesimally distinct moments form an elaborate continuum that carries us into an unknown and ever-changing future, we rely upon education to equip us with the practical and theoretical vocabularies necessary to survive and prosper, as well as to prepare the next generation for a potentially unknown future. This is no elementary task, and its daunting complexity and numerous symbioses are only magnified when one considers how the wondrous volatilities of the universe render us incapable of formulating any reasonable sort of portrait of our future world.

Despite the overwhelming nature of the role which education seems destined to play in our society, I believe that a large portion of the potential for its harmonious presence and prosperous evolution resides in the form of educational institutions and structured knowledge acquisition, though not in their current operational form. With regard to the history of human civilization, the presence of public education systems is a relatively modern phenomenon. Their existence was scarce prior to the early 19th century, when their popularity grew dramatically to meet the needs brought about by industrialization. Naturally, the primary objective of these institutions was to produce acceptable industrial workers, and the production of such was approached in a relatively industrial manner. Curricula underwent standardization and a kind of hierarchy was established among the disciplines in which one was instructed at school, with those disciplines most conducive to efficient performance in the industrial sector and on the professional scene (mathematics and language studies, for example) residing at the top. This format was quite suitable for the needs and conditions of times past, and the fundamental elements of such have remained embedded in the educational infrastructure up to the present time: the hierarchy of scholastic disciplines endures as "alternative" disciplines such as art, music, dance, drama, philosophy, and even physical education continue to grow scarcer as they are perpetually phased out of the conventional elementary/high-school curriculum model. I argue that this hierarchy is (as well as are other elements of the standard model for institutionalized education) unacceptable. It is potentially to the detriment of self-knowledge, emotional intelligence, and intellectual diversity, and results in personal alienation and underdevelopment, ultimately culminating as a manifestation of apathy, un-fulfillment, inefficiency, and cultural monotony. Clearly, the conditions and needs of the present differ greatly from those of the past. Education is ready 
to evolve. The previously valid assertion that academic credentials lead directly to professional success is waning drastically. One need look no further than our planet's rapidly expanding population, coupled with statistically evident increases in matriculation from multiple levels of education at an exponential rate around the world (UNESCO, 2011). Diplomas and standardized, certified knowledge acquisition are still vital to success in many domains, but are no longer sufficient alone.

So what is true success, and what is the secret to obtaining it? Simply put, success can be defined in the utilitarian terms of pain and pleasure (not unlike those commonly employed by 18th-century philosopher Jeremy Bentham), namely, that a successful person maximizes the latter and minimizes the former in all aspects of his or her existence. This is quite straightforward. A functional and progressive society, therefore, is one in which all members must work in order to contribute to their own pleasure, hence the pleasure and conducive progress or "success" of the whole. The more time we spend working in this manner, the more prosperity we can expect to experience as individuals and as a society. I would further argue that we experience pleasure when we are nurturing our passions.

In an organic world of relativity and perceptual bias both outwardly and inwardly directed, this notion of self-derived pleasure and fulfillment provides a very satisfactory (although abstract) definition of "success." Consider the relevance of this passage from "The Wealth of Nations" by 18th-century philosopher and economist Adam Smith (1776): "By pursuing his own interest he frequently promotes that of the society more effectually than when he really intends to promote it" (pp. 488-489). Does there exist a worthy description of a utopian society that is not established upon the profound transcendental satisfaction and productivity of its members?

Although this definition may resonate deeply with the minority whose passions are already flourishing, others may merely view it as a romanticized dramatization of a delusive, ecstatic paradise. The occidental world has always supported the feeding of an obsession with a breed of radical individualism or "cult of the individual or celebrity," which displays a rather absurd and dissuasive tendency to favor destiny, fate, and uncanny natural ability over self-knowledge and discipline as the most prominent sources of the aforementioned definition of success.

An ideal educational system is therefore one whose design is most conducive to establishing an environment in which individuals are provided with the resources necessary to locate their passions, learn to nurture and hone them, and apply/pursue them as a means to the evolving and progressing pleasure and prosperity of their 
individual selves and society on the whole. It should embody self-discovery and knowledge-of-self, community and communication, discipline, diversity, creativity, and a dynamic ability to learn both independently and with others.

This seemingly utopian, yet simple formulation fails to take into account that passion, talent, and intelligences are diverse as well as local. Earth boasts an everexpanding population of billions of human beings, each a potentially passionate, successful, and fulfilled individual. The range of these varied passions is simply huge, and the validity of each is justified by the definition of an individual, authentic self. The problem is that such a massively diverse spectrum of people, talents, intelligences, and passions calls for an educational system which consists of an equally diverse, personalized, and localized curriculum conducive to meeting the conditions under which society and its members may flourish. Such an approach must be organic rather than linear, in the sense that the comprehensive diversity of human passion and intelligence must be respected by initially facilitating introspection, self-knowledge, and academic independence at an early age, and by providing the resources necessary to refine and cultivate talents, intelligences, and passions. It entails the design of personalized curricula adapted to the respective strengths, weaknesses, and interests of its students, regardless of any impersonal predetermined prospects of success that may influence students' available educational resources or progressions.

This is far from the industrial, non-local, and impersonal "take it or leave it" system in which human diversity and potential is stifled by the aforementioned "disciplinary hierarchy." We cannot continue to sanction the conformity of authentic individuals to an outdated and unnecessary educational mould without actively endorsing alienation, indifference, and ignorance on a personal and societal scale.

\section{My Unique Home School Experience}

I was born in 1992 (in the Laurentian mountains some 100 kilometres north of Montreal). I am the first child of two professional artists: my father, an American composer, instrumentalist, and vocalist, and my mother, an Anglo-Canadian ceramic artist and educator. When I was young, my parents made the decision not to enroll me in a formal educational institution, after experiencing several encounters with children and adolescents who had been educated using alternative methods. This decision was further bolstered by the inadequate academic and social standards of the institutions available in the area. It is worth noting that both of my parents lead successful, active, passionate lives as well as highly fulfilling professional careers. 
After I was born, my father continued to support the family financially by composing, performing, and recording music, while my mother largely assumed the role of educator until I began secondary-level study. Every day for several years I was given what seemed like an endless amount of time to explore nature and cultivate a harmonious relationship with flora and fauna (and eventually their nomenclature and mechanics). I was also immersed in many diverse environments and circumstances, which I was constantly encouraged to analyze and critique. I believe that a great deal of introspection, observation, and critical thinking occurred during numerous experiences over this period. Here is a typical memory from a day in my seven-year-old life: The forest. Barreling up a Laurentian mountainside with my mother, reciting lessons in arithmetic and grammar aloud, enveloped by the tranquility of a crisp, country morning. Upon reaching the summit, we consult a plant field guide and spend the next few hours recognizing, classifying, studying, and drawing an abundance of native botanic specimens. Returning home, I help my mother in the kitchen and summarize my discoveries and reflections of the morning's exploits (over a homemade lunch prepared using fresh vegetables from our backyard garden), perhaps recording them in a journal. The afternoon would be dedicated to practicing Bach's The WellTempered Clavier, and in the evening, we would select stories and poetry which we would read to one another before bedtime.

Our home had an enormous selection of literary material, which I was encouraged to study at an early age, and my parents frequently read to me from a vast collection of classic children's literature including the works of Aesop, Charles Dickens, Lewis Carroll, and Mark Twain. My literary skills began to take shape at age three, and by age five I was reading Time Magazine (among many other publications) and had acquired a more dynamic initiative in the selection of the media that I was to consume (although television hours were a scarce occurrence, not to mention nonexistent during my early childhood). Given that my parents were accomplished, educated artists, exposure to a comprehensive spectrum of creative mediums was inevitable. I was introduced to drawing, painting, sculpture, ceramic, poetry, dance, theatre, and, most importantly, music. As both of my parents were pianists (my father a professional), I devoted many hours to playing and practicing classical and contemporary piano pieces guided by their teachings (when I became a teenager I transposed the practice of piano to the guitar). Many lessons were communicated via musical mediums both theoretical and intuitive, and music has remained a fundamental element of my cultural, professional, and expressive existence. I have been performing music alone and with my father since I was a young child, and still spend a great deal of time practicing and studying music each day. In addition to musical stimulation, I routinely accompanied my parents to the museum where we would study pieces and draw them for hours on end. 
But my educational resources were not limited to my family's initiative and my own personal means: we became loosely affiliated with a local "resource group" of families who had chosen "alternative" approaches to their children's education, and many classes/activities in the realms of science, art, languages, and physical education were organized either by members of the community or by selected specialists. In addition, I took part in numerous pedagogical and social activities involving friends who attended traditional school. Although I have always been characteristically introverted, I still enjoyed an extensive social life. In general, my early childhood was a period of exploration, immersion, and stimulation with respect to culture, intellectual/literary skills, and the physical world. I did not begin to develop any type of structured, regimented academic schedule until age eight, when I displayed a particular interest in mathematics and the sciences. Even though I had to devote many more hours to my studies at this time, I was still given much freedom to indulge in other activities such as music and athletics.

As for my scholastic endeavors, the attention, effort, and instruction that I received from my parents (particularly my mother) and also from outside sources remained significant until I began secondary-level education and started to exercise more initiative in setting my own goals. My interests and passions were gradually refined to include mathematics, physics, music, and athletics (particularly the Korean martial art of Taekwondo), each of which I actively pursue to this day. From then on, I became primarily responsible for my education. Most of my time was devoted to the study, practice, and exploration of these interests and passions. I acquired numerous courses and textbooks to study, conducted and recorded experiments, practiced and performed music, trained competitively and recreationally in Taekwondo-even though the discipline required to do so stemmed not from expectation or imposition, but from within myself. My greatest asset was not natural talent, but the ability to establish and pursue goals (as well as acquire knowledge) independently, rigorously, and confidently. By age $16 \mathrm{I}$ had enrolled in a correspondence program and eventually obtained official certification for many courses including those of the standard curriculum. I am currently studying science at Marianopolis College, and plan to study physics at university. 


\section{Conclusion}

Education is intricately interconnected with virtually every aspect of society. Perhaps the concept of a utopian infrastructure is simply fictional, but there are always improvements to be made. I have been truly blessed by unusual and extraordinary circumstances with regard to my family and the people around me, opportunities available to me and the encouragement to pursue them. While my own unique experiences certainly do not in any way amount to an enlightening example of some objectively valid ideal, I believe that there are elements of such experiences which could be very conducive to the design of an organic, personalized, and dynamic educational model that promotes and celebrates self-knowledge, creativity, discipline, passion, and diversity among current and future citizens of the world.

\section{References}

Einstein, A. (1949). Autobiographical notes. (Paul Schilpp, Translator and Editor).
UNESCO Institute for Statistics. (2011). Global Education Digest 2011, pp. 15-49

Smith, A. (1776). The wealth of nations, Book IV,

Chapter II.

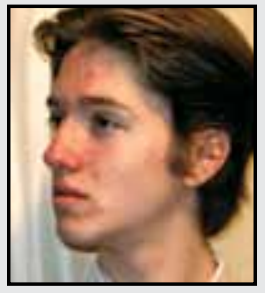

Eli Gerber was born in 1992 and educated independently of traditional schooling. He is a professional musician, a student, and Taekwondo practitioner who has held several regional, provincial, national and North American tournament titles. He is currently studying science at Marianopolis College with the ambition of becoming a physicist. 